This is a self-archived version of an original article. This version may differ from the original in pagination and typographic details.

Author(s): Vehkakoski, Tanja

Title: "Can do!" Teacher Promotion of Optimism in Response to Student Failure Expectation Expressions in Classroom Discourse

Year: 2020

Version: Accepted version (Final draft)

Copyright: (c) 2019 Scandinavian Journal of Educational Research

Rights: In Copyright

Rights url: http://rightsstatements.org/page/InC/1.0/?language=en

Please cite the original version:

Vehkakoski, T. (2020). "Can do!" Teacher Promotion of Optimism in Response to Student Failure Expectation Expressions in Classroom Discourse. Scandinavian Journal of Educational Research, 64(3), 408-424. https://doi.org/10.1080/00313831.2019.1570547 


\section{RESEARCH ARTICLE (Final Draft)}

\section{'Can do!' Teacher Promotion of Optimism in Response to Student Failure}

\section{Expectation Expressions in Classroom Discourse}

Tanja M. Vehkakoski, PhD, Docent, Senior Lecturer*

Published in the Scandinavian Journal of Educational Research (year 2020, vol 64, number 3, pages 408-424)

*University of Jyväskylä, Department of Education, P.O. Box 35, FI-40014 University of Jyväskylä, Finland. Email: tanja.vehkakoski@jyu.fi.

\footnotetext{
Acknowledgements

This study forms part of a larger research project entitled 'Something special in pedagogy? Classroom interaction in special education settings'. The project was supported by a postdoctoral fellowship from the Academy of Finland.
} 


\title{
‘Can do!' Teacher Promotion of Optimism in Response to Student Failure Expectation Expressions in Classroom Discourse
}

\begin{abstract}
:
This study offers detailed observational analyses of how teachers use optimism as an instructional resource when responding to students' failure expectation displays in classroom situations. The results were based on video-recordings of 25 lessons in two Finnish part-time special education settings, analysed by means of applied conversation analysis. The results showed that the teachers boosted optimism by inverting students' negative utterances, giving examples of successful experiences of peers, offering praise for students' earlier performance or focusing on problems through instructional support. The study underlines the importance of addressing and elaborating students' negative learning-related self-assessments in classroom interactions.
\end{abstract}

Keywords: teacher optimism; failure expectation; assessment; classroom interaction; conversation analysis 


\section{Introduction}

Optimism, that is, one's hopeful, favourable and confident future prospects (Jarrett \& Payne 2000; Scheier \& Carver, 1985) or anticipations of positive outcomes and success (Scheier \& Carver, 1985; Schulman, 1999; Nonis \& Wright 2003), has been found to be integral to student learning and optimised functioning. There is research evidence showing that students' optimism has positive effects on their schooling, such as school adaptation (Chemers, Hu, \& Garcia, 2001; Patterson, 2011), learning motivation (Phan, 2016), self-directed learning (Lounsbury, 2009) and academic performance (Chemers et al., 2001; Luthans, Luthans, \& Jensen, 2012; Nonis \& Wright, 2003; Phan, 2015; Ruthig, Haynes, Perry, \& Chipperfield, 2007; Tetzner \& Becker, 2017; TschannenMoran, Bankole, Mitchell, \& Moore, 2011; Wesson \& Derrer-Rendall, 2011). It has been suggested that the association of optimism with academic achievement is due to the students' greater persistence with learning tasks even after experiencing challenges (Tetzner \& Becker, 2017). Conversely, optimism may also be undesirable and contribute to negative outcomes, if it is in contradistinction to reality (Haynes, Ruthig, Perry, Stupnisky \& Hall, 2006; Held, 2002).

The importance of optimism can be grounded in positive psychology, the focus of which is on human strengths and positive individual qualities and their fostering in young people (Seligman \& Csíkszentmihályi, 2000). Optimism is traditionally considered to inhere in one's thoughts about goals, and therefore it is closely related to the concept of hope (Rand, 2009). However, while hope is only related to one's belief in his or her capacity to produce various routes to and achieve the desired goals (Rand, 2009; Snyder, 
2002), optimism can also be delineated as an expectation of success in one's life in the event of accidents and losses outside of one's control (Rand, 2009; Scheier \& Carver, 1985).

Although the influence of students' and teachers' optimism on student learning is well established in the literature, little is known about the details of the actual sequences through which situational optimism is promoted in classroom interactions in natural classroom settings. Indeed, the management of optimism as an interactional phenomenon has been studied only in difficult circumstances such as health and mental health care (Beach, 2003; Jarrett \& Payne, 2000; Martinez, 2009; Peräkylä, 1991), whereas research about promoting optimism in authentic teacher-student interactions, where student experiences may be stressful but less severe, is lacking. Therefore, this study aims to add to the earlier literature by offering close observational analyses of the ways in which teachers boost optimism in their talk, when students expect to fail in their learning and how students respond to these efforts by their teachers in actual classroom interactions.

The study is based on the principles of conversation analysis (CA) and its supposition of the management of optimism as a dynamic and sequentially organized process (Heritage, 2009). Since the fundamental idea of CA is to focus on talk, such as teachers' optimistic remarks in interactions without reference to the psychological characteristics of teachers or students, optimism is approached here as a communication act rather than as an internal state of mind (Heritage, 2009; Peräkylä, 2011). Therefore, the focus is on how optimism is invited through classroom talk and how teachers use promoting optimism as an instructional resource when responding to the students' expressions of failure expectation in their second position assessments. Since both 
promoting optimism and receiving optimistic messages are tightly intertwined and collaboratively negotiable, the focus is on both the teachers' and students' activities in classroom interactions in order to distinguish common features in the production of effective optimism-fostering messages. Thus, although the following specific research questions separate the ways in which teachers promote optimism from student responses, the focus is always on the joint action between students and their teachers in classroom interactions: 1) How do teachers promote optimism in response to students' failure expectation displays? 2) How do students respond to teachers' efforts to move toward optimism in the sequences of interactions between students and teachers? 3) To what kinds of interactional ends are both failure expectation displays and optimistic remarks used in joint negotiations between teachers and students in classroom interactions?

\section{Various Strategies for Promoting Optimism}

Managing optimism has been defined to mean 'the interactional construction of hopeful and optimistic responses to uncertain and potentially despairing circumstances' (Beach, 2003). It can be understood as a part of supportive communication, the purpose of which is to improve another person's psychological state (Jones \& Bodie, 2014). Earlier research shows that professionals use many means to promote optimism in order to resist people's displays of pessimism and expectations of failure. These discursive means include paying selective attention to positive news or the positive side of things (Benwell \& McCreaddie, 2016; Jarrett \& Payne, 2000; Peräkylä, 1991), orienting to neutral and factual elements of trouble-telling (Benwell \& McCreaddie, 2016), changing the subject when it evokes negative emotions (Benwell \& McCreaddie, 2016; Martinez, 
2009), disagreeing with negative utterances (Matsuoka, Smith, \& Uchimura, 2011) and turning such utterances into jokes (Jarrett \& Payne, 2000). In addition, professionals may aim at displaying optimistic knowledge (Jarrett \& Payne, 2000) by expressing their own confidence in people's possibilities (Matsuoka et al., 2011; Peräkylä, 1991), giving examples of others like them who were successful and reminding people of their previous successes and emphasising their strengths and future capabilities (Martinez, 2009). Furthermore, professionals can minimise and contextualise the difficulties met by their clients (Jarrett \& Payne, 2000; Martinez, 2009), give reasons for their failures (Jarrett \& Payne, 2000; Martinez, 2009) and normalise people's experiences by comparing them to their own experiences (Martinez, 2009). These strategies also partly resemble Bandura's (1977) notion of verbal persuasion, which also consists of techniques such as leaning on students' own progress or significant others' faith in their capabilities to raise students' outcome expectations and boost their self-efficacy (Bandura, 1977, 1997; Urdan \& Schoenfelder, 2006).

Optimism boosting has also been criticised as a less person-centred form of supportive communication that may lead to the suppression of people's emotion talk and avoidance of exploring it by minimising their problems or treating their fears as insignificant (Clark, MacGeorge, \& Robinson, 2008; Jones \& Bodie, 2014). While this may be well intentioned, with the aim to focus on overcoming stressful situations, due to their tendency to ignore emotional displays, such messages are not as effective as more elaborative support strategies (Burleson, 2003; Clark et al., 2008; Jones, 2004). Instead, the most effective and supportive means of promoting a more positive perspective on stressful experiences and improving one's confidence in one's ability to cope in 
achievement situations seems to be the use of highly person-centred support messages. These messages explicitly encourage people to share their fears of failure, legitimise their displays of difficult emotions and, above all, explicitly elaborate their expressions of fear and construct alternative viewpoints on stressful achievement situations (Bodie \& Jones, 2012; Clark et al., 2008; Jones, 2004; Jones \& Guerrero, 2001).

\section{Promoting Optimism as a Response to Students' Failure Expectation Expressions}

This study illustrates how teachers promote optimism in classroom interactions after the student has reported a failure expectation and thus claimed and/or demonstrated a lack of optimism. From the intra-psychological perspective, failure expectation, that is, negative beliefs about one's coping abilities, weak confidence in one's subjective chances of success in difficult situations and a fear of making errors (see e.g. Aunola, Stattin, \& Nurmi, 2000; Mancini, D’Olimpio, \& Cieri, 2004; Määttä, Nurmi \& Stattin, 2007; Määttä, Stattin, \& Nurmi, 2002), is considered to be one of the most maladaptive and selfhandicapping worries students face in achievement situations. It is connected with negative academic emotions such as anxiety, worry or hopelessness (Pekrun, Frenzel, Goetz, \& Perry, 2007) and predicts subsequent maladaptive behaviours, including taskavoidance, task-irrelevant activities and passivity in achievement contexts, as selfprotecting strategies (Määttä et al., 2002; Urdan, 2004). The effect of failure expectation on school performance occurs through this kind of maladaptive behaviour, which, in turn, is likely to lead to academic dissatisfaction (Nurmi, Aunola, Salmela-Aro, \& Lindroos, 2003), low learning achievement (Fyrstén, Nurmi, \& Lyytinen, 2006; Nurmi et al., 2003; 
Onatsu-Arvilommi et al., 2002) and increased internalisation and externalisation of problem behaviours (Aunola et al., 2000; Määttä et al., 2007). The former learning experiences are a key to developing failure expectation, since earlier performance and achievement seems to predict students' subsequent academic self-concept (Frost \& Ottem, 2018; Viljaranta, Tolvanen, Aunola, \& Nurmi, 2014).

Failure expectation expressions and other negative verbalisations of learning such as 'I don't understand', 'I can't get it' or 'I don't know' occur frequently in classroom interactions (Lindwall \& Lymer, 2011). However, although these constructions are literally concerned with the students' ability or their level of understanding, the functions of these formulations vary (Beach \& Metzger, 1997; He \& Tsoneva, 1998; Lindwall \& Lymer, 2011). In addition to showing non-understanding, claiming insufficient knowledge or asking for guidance from a teacher (Lindwall \& Lymer, 2011), the formulations may be used for introducing a complaint (Depperman \& Schmitt, 2008; Lindwall, \& Lymer, 2011), resisting or avoiding on-going activity (Beach \& Metzger, 1997; Hutchby, 2002; Lynch \& Bogen, 2005; Metzger \& Beach, 1996), implementing topic transition (Beach \& Metzger, 1997) and expressing frustration over or criticising tasks (Deppermann, 2012; Lindwall \& Lymer, 2011). These non-literal meanings of failure expectation utterances often appear in the extreme case formulations such as 'I don't understand anything', without any specification of a problem or talk about the details of a particular task that has provoked the anticipation of failure (Lindwall \& Lymer, 2011). Thus, in CA terms, students' failure expectation expressions are above all social signals, which are used to serve some functions in classroom interaction and which are also publically managed and oriented to somehow by teachers (see Ruusuvuori, 2013). 
From the CA perspective, students failure expectation expressions can also be considered as first position self-assessments in relation to which, in order to (co)participate in the same activity, teachers have to position their second assessment either by accepting, deconstructing or reconstructing the original failure expectation display (Heritage \& Raymond, 2005; Pomerantz, 1984). Simultaneously, the students and teachers claim access to the knowledge of what they are assessing, that is, of students' future performance and possibilities for success (Heritage \& Raymond, 2005; Heritage, 2011; Pomerantz, 1984). The first assessments usually suggest epistemic primacy (Heritage \& Raymond, 2005), while confirming, upgrading and agreeing with them are generally preferred actions on the part of the teachers (Pomerantz, 1984). This is especially the case when the first position assessment refers to a student's own mental state, such as feelings and experiences (e.g., failure expectation displays), as experiencer subjects are thought to have primary access to and ownership of them (see Heritage, 2011; Pomerantz, 1984). On the other hand, agreement with negative self-assessments and selfdeprecations such as failure expectation displays is not typically a preferred response, whereas disagreements with them can be considered as a sign of showing support (Heritage \& Raymond, 2005; Pomerantz, 1984). Examining students'self-assessments related to the hypothetical claims about future learning or performance could add to existing research on producing assessments, as earlier research has mainly concentrated on assessments referring to experiences and events that have occurred in the past (see Lindström \& Mondada, 2009) rather than to something that will occur only in the (foreseeable) future. 


\section{Method}

Data

The research data consisted of videotaped recordings of classroom interactions in two Finnish part-time special education settings: a primary school setting of grades 1-2 $(\mathrm{N}=12$ videotaped lessons) and a lower secondary school setting of grades 8-9 (N=13 videotaped lessons). Part-time special education was provided in conjunction with mainstream instruction, such that the students received special education for 2-3 hours a week only in those subjects in which they had minor learning or motivation difficulties (mathematics and languages). The part-time special education settings ensured finding information-rich classroom situations congruent with the purpose of the study, as students with learning difficulties have been found to be more likely to express low self-efficacy and display failure expectations and performance avoidance orientation compared to other students (see Jungert \& Andersson, 2013; Schwab \& Hessels, 2015; Yuen, Westwood \& Wong, 2008). Therefore, the reactions of teachers are especially important, and such students benefit significantly from strong instructional and emotional support in their everyday interactions with teachers (Hamre \& Pianta, 2005; Mashburn et al., 2008; Rudasill, Gallagher, \& White, 2010).

Both part-time special education settings consisted of small groups ranging in size from 3 to 8 students. Since the composition of the classrooms varied in the different lessons, the total number of students participating in this study was 31 . In the lower secondary school setting, there was one special education teacher (SET), while in the primary school setting a special education teacher and a kindergarten teacher taught collaboratively. The lessons were each 45 minutes in duration and consisted mainly of 
teacher-directed whole-group instruction and independent study. In the latter context, the instructional interactions often occurred in one-to-one formats.

The interactions were videotaped by the author using two cameras, with one camera following the teacher and the other focusing on the students. The videotaped classroom lessons were not specifically designed for this study but rather took place as a part of the normal school day, without outside intervention in the lessons. Thus, in contrast to only interviewing teachers concerning their practices, the observation data provided an authentic opportunity to capture what actually happens in instructional interactions when students express their expectation of failing in future tasks and when teachers try to boost optimism. Despite the presence of the cameras, the lessons appeared to progress smoothly, and videorecording did not seem to interrupt the emergence of sensitive topics (e.g. confiding in the teacher, negative self-talk) or socially undesirable behaviour (e.g. sulkiness, complaining, teacher resistance) in the lessons. However, there were a couple of episodes where students showed that they were aware of the videotaping by commenting either on the camera or the camerawoman in some way (e.g. 'yikes, the camera', 'hey, look at and film me', 'where is that princess [referring to the camerawoman], oh she is over there'). Permission for recording the classroom interactions was requested from each study participant, and informed written consent was received from all students and their parents.

\section{Analysis}


The data were analysed by applying ethno-methodological conversation analysis (CA). The microanalysis of the on-going process of classroom interaction shows how teachers and students locally interpret what is going on and what is consequential in the immediate interactions. The basic principle of CA is to interpret the meanings of utterances on the basis of the next action, or later turns (Heritage, 2001, 2005). Thus, the consequences and meanings of failure expectations and optimistic messages were primarily concluded by examining how students and teachers interpreted each other's intentions and responded to each other's turns.

In practice, the analysis was started by coding all failure expectation sequences from the data. The following criteria were used to identify these critical sequences: 1) students explicitly topicalised their failure expectations as first position self-assessments by expressing that they were not capable of learning, not able to do something or not capable of being successful in future challenges; 2) these comments existed prior to attempting to accomplish a task or part of it, an examination or some other activity. Typically, this appeared as the use of the present or future tense when anticipating failure. A qualitative data analysis system (ATLAS, version 5.0) was used to manage the data during this preliminary analysis.

After the coding phase, the failure expectation sequences were examined more deeply in order to identify recurring patterns in the interactions and to determine what to finally look for in the data. Teachers' optimism-boosting responses emerged as the focus of study during this phase of analysis once their dominance in response to students' utterances became apparent. Optimism-boosting responses refer to the teachers' immediate second position assessments subsequent to students' prior negative self- 
assessments, which are oriented to addressing students' possibilities for favourable future prospects, positive outcomes and success. The further analysis thus concentrated on this aspect of the data, that is, the grammatical features and the differences and similarities of the ways in which teachers promoted optimism in response to students' failure expectation expressions, as well as the students' responses to these efforts of their teachers. There were 52 total sequences where teachers aimed at promoting optimism in response to students' failure expectation expressions. Each sequence might contain repeated students' failure expectation expressions as well as several teacher attempts to boost optimism in the students.

The reader can assess the credibility of the interpretations by comparing them to the authentic data examples included in the results section. According to the tradition of $\mathrm{CA}$, the data are presented as complete interactional sequences to enable the reader to recognise the interactional context of invoking optimism in response to failure expectation expressions. The transcriptions followed the detailed transcription conventions used in the CA tradition (see Appendix 1). However, the transcriptions of the data did not include all such details (e.g. the length of the micro-pauses, length of gaze) that would have been typical in CA tradition but which were not as fundamental from the viewpoint of this analysis. Thus, the analysis represented applied rather than pure CA, aiming at mainly applying CA knowledge to optimism promotion in the classroom context (see ten Have, 2007, pp. 7-8). The confidentiality of the study participants was ensured both in the data excerpts and in the descriptions of the research settings. The original language of the data extracts was Finnish, but they were translated into English with the assistance of a language consultant. The translation required balancing between 
the literal and idiomatic translations so that the form of the original text would be respected as much as possible while the turns would evocate the same shades of meaning despite the differences in established phrases between languages.

\section{Results}

Sequences involving students' failure expectation expressions start with the students giving a negative comment about their future learning. This appears in expectations of failing in the examinations (e.g. 'I'm gonna get a four ${ }^{1}$ on that test, too'), pessimistic remarks about coping with independent classwork or homework (e.g. 'nothing will come of this') or reluctance to answer a teacher's questions in the context of task checks ('no, it will be wrong'). Thus, the pedagogical context in which students reveal something about their failure expectations seems to be one in which they have to prove their knowledge and understanding in some way. The teachers move toward optimism to counteract this lack of optimism by inverting the students' negative utterances, giving examples of the successful experiences of peers, offering praise for students' earlier performances or focusing on the problems through instructional support. In the following sections, each of these ways to promote optimism is presented along with the students' responses.

\section{Inverting Students' Negative Utterances}

The most typical way in which teachers boost optimism in response to student failure expectation expressions is simply to disagree with them and invert the students' negative

\footnotetext{
${ }^{1}$ The grade 'four' is a failing grade on the Finnish grading system scale (4-10).
} 
utterances. These second position assessments are typically short and simple, following the form of the student's earlier turn although contradicting its content (e.g., a student claims that 'I can't do something' and a teacher answers, 'yes you can'). Inverting students' negative utterances occurred in $52 \%$ of the sequences where teachers aimed at promoting optimism in response to the students' failure expectation expressions, and in addition to this, it was also foundational to the other practices of boosting optimism. Through these kinds of responses, teachers directly contradict the validity of students' prior assessments about the lack of optimism and minimise the existence of learning problems by expressing confidence in the students' coping potential. The following extract from the first graders' Finnish language lesson is an example of this way of using optimism as an interactional resource.

Extract 1: The Pinewood School, 1st grade, Finnish language

SET: $\quad$ okay (2.0), now we get to play detective (1.0) now everyone has ((raises right hand, holding a piece of white paper)) has on this blackboard there (.) ((points into the hallway)) >then you too< (.) have (1.0) words (.) turned upside down (.) and your job is (.) to turn the word (.) ((turns the word as an example)) >let's look at an example now<

Gloria: I ICAN'T READ ((the kindergarten teacher, teacher 2, is close to Gloria and whispers something; the special education teacher does not react at all))

6

7 SET: $\quad$ turn the word (.) and find out $\uparrow$ what it might say

8 Gloria: I CAN'T [READ

9 SET: there is] in this word now (.) look (.) there are (1.0) how many syllables? ((the teacher is holding a paper with a word on it, which she shows to the students; the students are guessing))

SET: $\quad$ two syllables, the first of which is

13 ((both teachers continue to give directions; 1 minute and 40 seconds of text missing))

14 SET: $\quad \uparrow$ RAISE your hand if you understood what you have to $\uparrow$ do ((some hands are raised))

$15 \quad(1.0)$

16 A student: I $\uparrow$ understood

17 SET: $\quad$ good 

her head)) (1.0) without any doubt ((pats Gloria on her belly))

At the beginning of extract 1 , the special education teacher is giving instructions for the next task at the front of the classroom. Her co-teaching partner, the kindergarten teacher, stands at the side of the classroom, close to a student called Gloria. In the middle of the special education teacher's task-giving, Gloria declares loudly, 'I CAN'T READ'. The expression does not only refer to Gloria's lack of cognitive skills but, in one sense, may also act as a way of criticising the planned tasks for being too demanding. The protestation is also interactionally treated as problematic, which appears in the special education teacher's way of ignoring it and continuing the instruction-giving without looking at Gloria. Although the kindergarten teacher leans over the student, Gloria does not take this as an answer but rather repeats her failure expectation message in precisely the same words and with the same increase in volume. In turn, the special education teacher once again produces Gloria's attempted contact as unpreferred by refusing to respond to it and trying to keep the children focused on her instructions.

The episode initiated by Gloria is followed by a relatively long ( 1 minute 40 seconds) instruction sequence, after which the kindergarten teacher begins to move Gloria towards optimism (lines 17-19). The teacher cites Gloria's earlier turn, but departs from it by means of the questioning word choice 'as if'. At the same time, she strongly minimises the existence of the difficulties expected by Gloria with the following extreme modal expressions: 'you will absolutely surely find out those', 'always' and 'without any doubt'. In addition, the teacher's optimistic verbal remarks are supported by her 
nonverbal encouragement through touching and coming closer to Gloria. However, despite this, Gloria continues to signal resistance by shaking her head.

Thus, the teachers aimed at boosting optimism in extract 1 by inverting the students' negative utterances, such as not being able to read, to the positive talk, such as being able 'to find out those letters'. However, the optimistic remarks as second position assessments were not justified in any way, and therefore the disagreements with the experiences first narrated by the students remained unconvincing and unpreferred from their viewpoint. This was evident in that invoking optimism did not appear to produce the expected outcome, and the claims of the teacher and the students remained in disagreement.

\section{Giving Examples of Successful Experiences of Peers}

The second way teachers sought to boost optimism was to provide reasons for their optimistic orientation by sharing stories about the success of the students' peers who had been in similar situations. This way of promoting optimism remained quantitatively marginal in the data, occurring only in $4 \%$ of the sequences where teachers aimed at invoking optimism in response to students' failure expectation expressions. An example of how optimism is promoted through giving examples of successful experiences of peers can be seen in extract 2 , in which ninth grade students begin a practice exam in mathematics and display failure expectations. 
SET: hey er (.) umm (.) a piece of advice (.) a little advice (.) before you start doing anything (1.0) before you look at any of the tasks (.) $\uparrow$ mark on the paper $\langle\uparrow$ sine (.) cosine (.) tangent> ((shakes a finger at each word)) [and how they are calculated

paper? ((turns to look at the teacher))

SET: the whole paper needs to be done (.)

Lily: all- $\uparrow$ in one hour?

8 SET: yes [in four-

Lily: $\quad>$ no can do<]

SET: -ty minutes (.) can do (.) it went just fine yesterday ((nods her head)) there were $\uparrow$ no problems ((finally smiles at the student))

Evie: with who?

SET: umm (.) with one 9c student, ahem ((clears throat))

Lily: well $\uparrow I$ can’t do it ((returns to looking at her task paper))

SET: so write down that $\uparrow$ the cosine alpha is equal to and then the information (2.0) on how you will calculate it ((turns halfway through her speaking turn to observe what Evie marks on her paper))

Evie: *I'll probably forget everything* ((looks at her desk and takes the notes; the teacher only speaks again after Evie has lifted her eyes from her desk))

SET: and then take a look at the triangles ((continues giving instructions))

In the beginning of the extract, the special education teacher gives the students some advice on how to cope with the test. One of the students, Lily, interrupts the instructiongiving to make sure that the students really have to do 'the whole paper' during one lesson (lines 4 and 7). The teacher confirms the presupposition embedded in the yes-no interrogative question ('yes, in forty minutes'), and in response to this, Lily initiates the failure expectation sequence through the negation 'no can do'. The resistance to teacher's demand is expressed in a clipped style, immediately, and even partially overlaps with the teacher's turn. In addition, the so-called zero-person construction of the utterance frames the negative assessment as a generic and absolute fact that concerns the group as a whole, not only Lily herself (see Halonen, 2008). 
The teacher's first move toward optimism in line 9 is as absolute and generic as Lily's first position self-assessment, but its content has been inverted in the same way as in extract 1: 'can do'. Nevertheless, the teacher now provides confirming evidence for her optimistic remarks by providing information about a similar examination that 'went just fine' and without problems 'yesterday'. Furthermore, she specifies her optimistic answer in line 12 after another student, Evie, has asked her to whom she was actually referring in her description. The clarification indicates that the purpose of the teacher's message is to give the students a positive role model of a fellow student, with whose success they could identify. In this way, the teacher offers an alternative perspective on the situation that projects an optimistic outcome.

What is noteworthy about the extract is that, similar to in extract 1, the teacher's optimistic message is not shared by the students. Instead, Lily reconfirms her earlier assertion of future failure and questions the relevance of the role model by excluding the same possibility of succeeding herself: 'well $\uparrow I$ can't do it'. The content of this negation is voiced in the first-person singular and thus is only focused on Lily herself. After this, Lily turns to look at her paper on the desk and, in this way, shows that the topic can be terminated. The teacher also initiates a topic change by ignoring Lily's last comment and continuing to give instructions. The last negative throwaway comment regarding the low chance of success comes from Evie, who, while taking notes on the paper following the teacher's instructions, whispers: '*I'll probably forget everything*'. The teacher also disregards this self-assessment.

The extract thus shows how teacher optimism was justified by providing an example of peers who have succeeded in a fear-invoking situation that is parallel to the 
one the students report to be currently worrying. The peer identification is thus used to invoke the students' positive trust in their own coping abilities since they would not be the only ones who have managed in a similar achievement situation. Despite this, the students did not respond as expected by agreeing to the teacher's optimism but attached to their prior negative self-assessments. Once again, their rejection was produced immediately and directly without any explanations or delay in responding.

\section{Offering Praise for Students' Earlier Performance}

The third way to boost optimism is to offer praise for students' current skills and earlier learning successes. In this way, occurring in the $21 \%$ of the sequences, teachers prove the students' failure expectation expressions to be unrealistically pessimistic and not supported by their earlier personal learning experiences. This can be seen in extract 3 , which is taken from a classroom scenario that is similar to that in extract 2. Here, ninth grade students talk about an upcoming examination, and they again display apprehension.

Extract 3: Stenvall School, 9th grade, mathematics

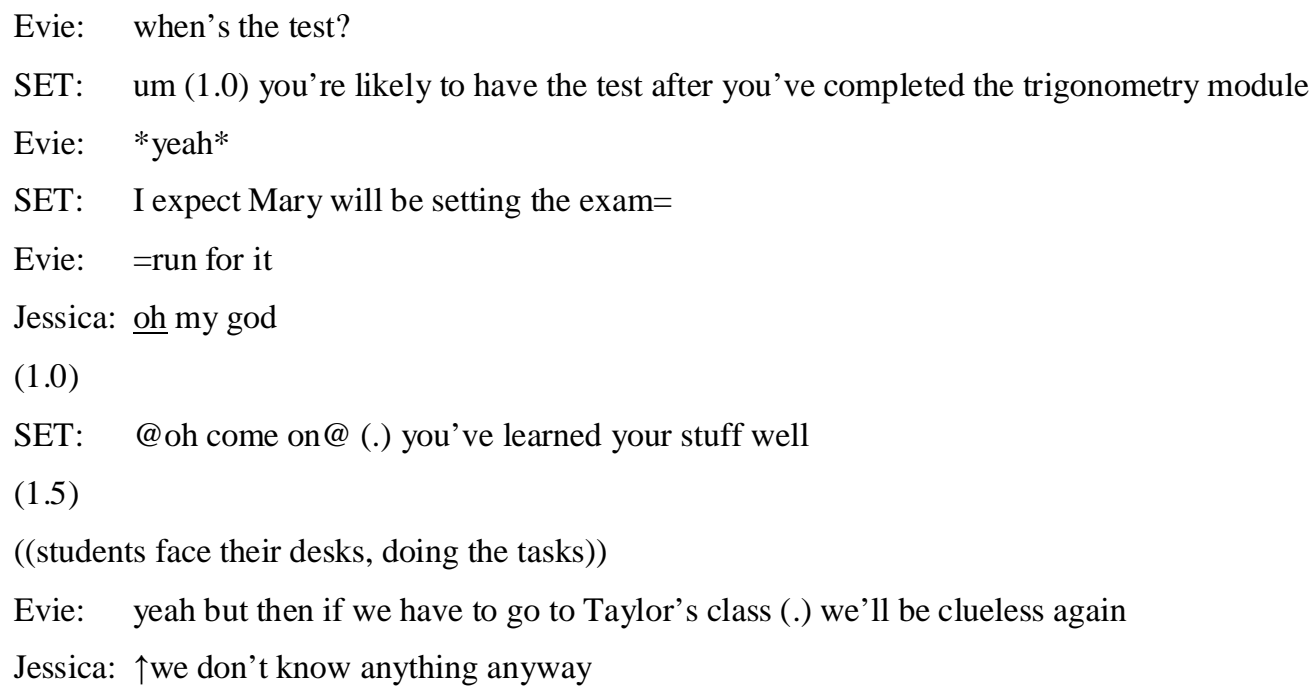


Evie: no we won't

SET: what you can or can't do doesn't depend on the place

18 Evie: yes it does (.) I mean it depends on the teacher

Evie: @\$no it doesn’t (.)no it doesn't\$@

In this extract, the failure expectation sequence starts with the special education teacher stating in line 4 that it is the students' subject teacher who will arrange the next examination. The teacher's comment immediately evokes fear-like exclamations from the students, such as 'run for it' and 'oh my god'. However, the tone of the groans is humorous, and thus the teacher responds to them by smiling and replying with a laugh, ‘@oh come on@'. The optimistic utterance is further strengthened by the praise that the teacher gives to the students for their earlier learning achievements: 'you've learned your stuff well' (line 8).

This optimistic remark is, however, accepted only partly by the students, who give a more detailed account of the required learning circumstances: learning can succeed in the part-time special education setting but will not in the general education lessons given by their own subject teacher in mathematics (lines 11-12). However, the teacher reboosts the students' optimism by challenging the negative assessments in line 14 and by giving a favourable appraisal of their potential to succeed in the general education classroom. The form of this optimistic message is similar to those in the previous extracts, being expressed factually in the form of the second person plural: ‘@you'll do just as 
well there too@'. The students, however, do not share in the teacher's optimism, and Evie discounts the claim immediately: 'no we won't'.

Evie's resistance is followed by a long pause, after which the teacher reattempts to invite a more hopeful and controllable alternative interpretation of the negative selfassessments produced by the students: the locus of control does not depend on external factors such as place (line 16). At first, Evie contradicts the teacher ('yes it does'), but she immediately corrects herself and revises her interpretation: learning does not depend on the place, but rather on the teacher. This comment leads to the same kind of refutation of the students' claims as earlier: the teacher provides grounds for optimism by aligning positive learning outcomes primarily with the students' own motivation to learn (lines 19 and 21). The expression contains a perspective-making utterance 'I actually think', which highlights the teacher's personal commitment to the content of the claim. Evie also maintains her own opinion and denies the teacher's optimistic messages unambiguously in lines 20 and 22 .

In sum, extract 3 shows how the teacher intervened in the students' failure expectation displays by trying to get the students to orient to their own personal control over their learning. Crucial to this was laying groundwork for optimism by referring to the students' own earlier performance. However, the arguments of the teacher did not carry conviction, and the students seemed to hang on to their prior negative selfassessments.

\section{Focusing on the Problems through Instructional Support}


The final means of boosting optimism is to draw the students' attention away from their failure expectation expressions and towards the task at hand through problemfocused orientation. In $23 \%$ of the sequences where teachers aimed at managing optimism, the teachers aim to steer away from the non-specific failure expectation talk of the students and focus on dealing with the concrete difficulties of the tasks at hand through providing instructional support. The following extract from the second graders' mathematics lesson is an example of this kind of instruction sequence, in which the teacher scaffolds one of the students for active engagement. The students are working individually with the decimal system during independent seatwork, and the special education teacher and the kindergarten teacher are walking around the room to see if anyone needs their help. Oliver has sat passively for some time, twisting his head and fiddling his fingers.

Extract 4: The Pinewood School, 2nd grade, mathematics

1 ((The special education teacher sits next to Peter and advises him regarding the task))

2 Oliver: \$I can't do it\$ ((moaning voice))

3 SET: yes you can (.) swimmingly

$4 \quad$ (2.0) ((the teacher takes a look at Oliver and then stretches to point with her finger to Oliver's 5 book))

6 SET: look just in the same way (.) Oliv- Oliver first (.) <how many hundreds> does that number (.) $7 \quad$ contain?

8 Oliver: two hundred and seven

9 SET: and you add <three> to it (.) colour three more boxes

$10 \quad$ (3.0) ((Oliver takes him pencil and begins doing the task $))$

11 SET: next check $\uparrow$ how many complete hundred boards there are

12 Oliver: *two hundred*=

13 SET: $=\mathrm{hm}-\mathrm{m}$

14 Oliver: two hundred (.) and ten ((takes a look at the teacher))

15 SET:@yay@ ((moves to advise Peter; Oliver continues completing the task)) 
In extract 4, the failure expectation sequence begins when Oliver breaks the silence and indicates in a moaning voice his withdrawal from attempting to carry out the set tasks: '\$I can't do it\$' (line 2). This orients the teacher immediately to stopping Peter's advice and asserting a more optimistic outlook for Oliver, leaning towards him and ensuring him that he is actually able to do the tasks well: 'yes you can (.) swimmingly'. The teacher's praise, however, is not the only means she uses to promote optimism. She begins to provide detailed advice regarding the next steps in completing the task. Although Oliver's failure expectation expression was general and it was not clear whether it referred to a specific task or the tasks under construction in general, the special education teacher's first instructional question was clearly task-specific: ' $<$ how many hundreds> does that number (.) contain?' Directing Oliver's thinking through this question focuses his attention on the specific task at hand and scaffolds him for active engagement. After Oliver has given a straight and correct answer to the question, the teacher offers two direct, concrete suggestions related to adding up the numbers and colouring the boxes. In consequence, Oliver focuses on the task and puts pen to paper upon the teacher's suggestion.

The instructional sequence is followed by a combination of a teacher suggestion ('check') and a sub question ('how many') in line 11. Oliver again succeeds in producing the right answer, which is followed by the cheerful interjection 'yay' from the teacher. This closes the instructional sequence, and the teacher leaves Oliver to complete the tasks independently and returns to advise Peter.

The extract demonstrated how the teacher systematically directed Oliver's attention away from failure expectation displays towards the task at hand through 
stepwise advice and teacher-directed guidance. The strategy seemed to be efficient, and the teacher and Oliver achieved joint understanding about how to progress with the task. Once Oliver picked up the threads of the tasks, he continued to complete them even after the teacher withdrew from advising. The student failure expectation expression was thus interpreted as a cue signalling real difficulties and a pre-request for assistance, which appeared in the teacher's way to concretely support Oliver in problem solving in addition to the optimistic verbal messages. The situation ended in Oliver's task-relevant behaviour, despite his initially stated self-assessment that he was incapable of doing so.

\section{Discussion}

This study aimed at documenting how teachers attempt to promote students' optimism in classroom discourse. The starting point for the study was the interaction sequences, where students expressed their failure expectations as the first position selfassessment and teachers aimed at moving the conversation toward increased optimism when producing second position assessments. The findings revealed that the typical sequential structure of teacher optimism boosting in response to students' failure expectation expressions consisted of three components. First, a student commented negatively on his or her future learning or task management. Second, the teacher aimed at promoting a more optimistic view either through inverting the students' negative utterances, or by justifying and expanding this positive second position assessment through giving examples of successful experiences of peers, offering praise for the students' earlier performance or focusing on the problems through instructional support. 
Third, apart from the last way of promoting optimism, the students resisted moves toward optimism by consistently negating them and continuing to voice their expectations of failure. The teachers in turn either ignored these new negative self-assessments, repeated their earlier optimistic comments or provided instructional support to encourage the students' engagement in the learning tasks.

Aside from the focus on students' problems through instructional support, the ways of promoting optimism similar to those found in this study have been used in other contexts such as social services and health care (Jarrett \& Payne, 2000; Martinez, 2009; Matsuoka et al., 2011). In this study, inverting the students' negative utterances was the most dominant practice through which teachers boosted optimism. In addition, it was also foundational to the other ways of promoting optimism. Inverting the students' negative utterances involved brief verbal influence attempts that did not contain reasons for teacher optimism, and the invoking of optimism was mainly used as a resource for quickly returning to the original task. In this way of using optimism, teachers' contrastive second position assessments were typically accomplished explicitly and immediately by means of declarative sentences without markers of hesitation or delay (cf. Pomerantz, 1984). This might be partly due to the negativity of the students' initial self-assessments, the preferred response to which is usually to show support through overt disagreement with them (Heritage \& Raymind, 2005; Pomerantz, 1984), as well as their declarative form inviting teachers to also present their optimistic assertions in the stated form.

Compared with inverting students' negative self-assessments, the sequences where teachers boosted optimism by producing examples of successful experiences of peers or by offering praise for the students' earlier performance consisted of several 
teacher turns and resembled verbal persuasion techniques also recommended by Bandura $(1977,1997)$. The teachers' method of providing reasons for their optimistic assessments invited the students to explore their self-assessments a bit more extensively and aroused more long-lasting turn-by-turn negotiation between students and teachers regarding the validity of the negative self-related claims narrated by the students. Thus, the use of simple optimistic remarks seemed to invite the students to only repeat their simple negative objections, whereas the expanded turns of the teachers also prompted the students to provide explanations for their negative self-assessments.

What was notable in the study was that when the teachers attempted to foster optimism, the students did not immediately agree with the optimistic remarks but rather resisted the teachers' optimism and returned to their earlier pessimistic talk. This kind of resistance has been found in earlier research (see Martinez, 2009; Peräkylä, 1991), although it also contrasts with previous findings (Beach, 2003). In terms of this study, the negotiation about optimism meant some kind of struggle between the students' primary epistemic rights to produce self-assessments about their own learning possibilities (Heritage \& Raymond, 2005; Heritage, 2011) and the teachers' primary institutional rights to evaluate the students' learning and related claims as well as to manage their behaviour in achievement situations. In addition, the orientations of the teachers and students towards optimism seemed to be somewhat incompatible. When expressing failure expectation, the students seemed to focus on emotional trouble telling, as described by various affective elements such as agitated or fear-like exclamations in their turns. Instead, rather than treating students failure expectation expressions as emotional displays requiring typically empathetic affiliation with the stance taken by the students 
(Heritage, 2011; Ruusuvirta, 2013), the teachers seemed to orient to them as factual and self-handicapping learning-related claims hindering the students from trying to learn (see e.g. Määttä et al., 2007; Urdan, 2004). Thus, the teachers did not focus on expanding these emotional elements of student assessments but rather oriented to refute them through simple negations or verbal persuasion aimed at appealing to the students' rational thinking and returning to the on-task talk as quickly as possible (see also Benwell \& McCreddie, 2016).

In addition to emotional trouble telling, the students also seemed to orient to the failure expectation expressions as requesting advice from teachers, implying the literal meaning of their failure expectation displays (see Lindwall \& Lymer, 2011). This interpretation is supported by the finding that the most productive way in which the teachers reacted to student failure expectation displays seemed to be problem-focused and learning-related classroom talk aimed at making the learning content more manageable by offering instructional support for solving the problem at hand. In the context of taskindependent classwork or whole-class task checks, where students' failure expectation displays were also followed by a refusal to continue accomplishing the task before receiving advice and guidance, the failure expectation expressions thus conveyed obligations for teachers to act according to the requests for help related to students' negative self-assessments. As for teachers, their optimistic remarks together with the specific instructional support served as a resource to encourage students to return to ontask activities and self-directed learning as well as to provide the students with a successful learning experience. These kinds of learning and achievement experiences have been found to be a key to shaping students' negative self-assessments to become 
more favourable in the future (see Frost \& Ottem, 2018; Viljaranta, Tolvanen, Aunola, \& Nurmi, 2014).

\section{Limitations}

There are some limitations to this study. The relatively small data size (three teachers, 25 recorded lessons) affects the generalizability of the analysis, as individual differences between teachers could have produced more variation in the ways that optimism was used as an interactional resource in the classroom interaction. The transferability of the research results is, however, justified by the presumption of CA, according to which interactions are reduced to institutionally shared teaching practices and are typically based on unconscious and non-reflected choices of action (Peräkylä, 2013) rather than on teachers' individual values or conscious ways of fostering optimism. Thus, every part of the interactions may reveal some general patterns of social order as well as potentially being generally significant for applications in other contexts (Peräkylä, 2004). This was also confirmed by the fact that although there was a wide range of students' ages in the data, the basic features of the optimism-promoting strategies used by the teachers were similar, which strengthens their transferability despite the different student ages and grades. However, it would be important for future researchers to test the findings of this study with a larger number of teachers. In addition, although the data extracts and preliminary interpretations were presented to and commented on in a conversation analysis group data session, involving teachers in the study as consultants to check the interpretations of the failure expectation sequences would have ensured that the interpretations were achieved through intersubjective agreement including the teachers. 


\section{Conclusions and Implications}

The results showed that the core of using optimism as an instructional resource was to invert students' failure expectation expressions either through brief encouraging phrases or through justifying the optimism by providing examples of successful experiences of peers, offering praise for the students' earlier performance or focusing on the problems through instructional support. However, what was missing from the teacher responses in the present study was an invitation for the students to further explore their negative self-assessments. Instead, the teachers' practices of moving towards optimism through using simple declarative sentences as well as challenging the validity of students' narrations about their future failures can be conceptualized to represent controlling instructional communication rather than autonomy supportive teaching (Froiland, 2018; Froiland, Davison \& Worrell, 2016), the idea of which is to acknowledge students' emotional displays and show appreciation for their perspectives. Therefore, instead of presenting overt disagreements with students' negative self-assessments, acknowledging the failure expectation displays through empathetic response tokens such as ' $\mathrm{mm}$ ' or ' $\mathrm{hm}$ ' and formulating them might be a pedagogically preferably choice of action which would validate the students' ownership of their personal knowledge (see also Heritage \& Raymond, 2005; Ruusuvuori, 2013; Su \& Reeve, 2011) and provide unconditional positive regard to them. In addition, using questions to prompt the students to voice their learning-related fears might invite the students to collaboratively elaborate their negative self-assessments, and in this way, gradually orient them toward producing favourable self-assessments about themselves and becoming more receptive to suggestions for optimistic expectations. Since the problem-focused way of promoting optimism seemed 
to be constructive in this study, providing instructional support would also acknowledge difficulties with the tasks reported by the students while providing them with concrete tools for successfully completing tasks and avoiding unsuccessful attempts.

While the findings of this study may need further confirmation using a larger sample of teachers and students from different cultures, awareness of the complexities of apparently well-phrased attempts to promote student optimism is of considerable importance in avoiding overly simple methods of promoting optimism. In the future, it would be worthwhile to study students' and teachers' own evaluations of optimism management in classroom interaction. Video recordings of discussions in which an interviewer and students watch and discuss recordings of invoking optimism in classroom discourse would be an optimal research strategy for eliciting participants' views and would supplement findings based purely on observational data. In addition, further research might also focus on how optimism is promoted by teachers in situations where failure is not only anticipated but where students also narrate their failure experiences or display negative emotions in the face of failures. 


\section{References}

Aunola, K., Stattin, H., \& Nurmi, J-E. (2000). Adolescents' achievement strategies, school adjustment, and externalizing and internalizing problem behaviors. Journal of Youth and Adolescence, 29(3), 289-306.

Bandura, A. (1977). Self-efficacy: toward a unifying theory of behavioral change. Psychological Review, 84(2), 191-215.

Bandura, A. (1997). Self-efficacy. The exercise of control. New York: W. H. Freeman and Company.

Beach, W. A. (2003). Managing optimism. In P. Glenn, C. D. LeBaron, \& J. Mandelbaum (Eds.), Studies in language and social interaction: In honor of Robert Hopper (pp. 148-164). Mahwah, NJ: Lawrence Erlbaum Association.

Beach, W. A., \& Metzger, T. R. (1997). Claiming insufficient knowledge. Human Communication Research, 23(4), 562-588. doi: 10.1111/j.1468-2958.1997.tb00410.x

Benwell, B., \& McCreddie, M. (2016). Keeping "small talk" small in health-care encounters: Negotiating the boundaries between on- and off-task talk. Research on Language and Social Interaction, 49(3), 258-271. doi: $10.1080 / 08351813.2016 .1196548$

Bodie, G. D., \& Jones, S. M. (2012). The nature of supportive listening II: the role of verbal person centeredness and nonverbal immediacy. Western Journal of Communication, 76(3), 250-269. doi: 10.1080/10570314.2011.651255

Burleson, B. R. (2003). Emotional support skill. In J. O. Greene \& B. R. Burleson (Eds.), Handbook of communication and social interaction skills (pp. 551-594). Mahwah, NJ: Lawrence Erlbaum Association. 
Chemers, M. M., Hu, L., \& Garcia, B. F. (2001). Academic self-efficacy and first-year college student performance and adjustment. Journal of Educational Psychology, 93(1), $55-64$.

Clark, R. A., MacGeorge, E. L., \& Robinson, L. (2008). Evaluation of peer comforting strategies by children and adolescents. Human Communication Research, 34, 319-345. doi: 10.1111/j.1468-2958.2008.00323.x

Depperman, A., \& Schmitt, R. (2008). Verstehensdokumentationen: zur phänomenologie von verstehen in der interaction. Deutsche Sprache, 36(3), 220-245.

Deppermann, A. (2012). How does 'cognition' matter to the analysis of talk-ininteraction? Language Sciences, 34, 746-767. doi: 10.1016/j.langsci.2012.04.013

Froiland, J. M. (2018). The intrinsic learning goals of elementary school students, in their own words. Journal of Humanistic Psychology. Advance online publication. doi: $10.1177 / 0022167818763923$

Froiland, J. M., Davison, M. L., \& Worrell, F. C. (2016). Aloha teachers: Teacher autonomy support promotes Native Hawaiian and Pacific Islander students' motivation, school belonging, course-taking and math achievement. Social Psychology of Education, 19(4), 879-894. doi: 10.1007/s11218-016-9355-9

Frost, J., \& Ottem, E. (2018). The value of assessing pupils' academic self-concept. Scandinavian Journal of Educational Research, 62(2), 264-271. doi: $10.1080 / 00313831.2016 .1212397$

Fyrstén, S., Nurmi, J-E., \& Lyytinen, H. (2006). The role of achievement beliefs and behaviours in spontaneous reading acquisition. Learning and Instruction, 16, 569-582. doi: 10.1016/j.learninstruc.2006.10.005 
Halonen, M. (2008). Person reference as a device for constructing experiences as typical in group therapy. In A. Peräkylä, C. Antaki, S. Vehviläinen, \& I. Leudar (Eds.), Conversation analysis and psychotherapy (pp. 139-151). Cambridge, UK: Cambridge University Press.

Hamre, B. K., \& Pianta, R. C. (2005). Can instructional and emotional support in the first-grade classroom make a difference for children at risk of school failure? Child Development, 76, 949-967. doi: 10.1111/j.1467-8624.2005.00889.x

Haynes, T. L., Ruthig, J. C., Perry, R. P., Stupnisky, R. H., \& Hall, N. C. (2006). Reducing the academic risks of over-optimism: the longitudinal effects of attributional retraining on cognition and achievement. Research in Higher Education, 47(7), 755779. doi: 10.1007/s11162-006-9014-7

He, A. W., \& Tsoneva, S. (1998). The symbiosis of choices and control: toward a discourse-based account of can. Journal of Pragmatics, 29, 615-637. doi:

$10.1016 / \mathrm{S} 0378-2166(97) 00056-8$

Held, B. S. (2002). The tyranny of the positive attitude in America: observation and speculation. Journal of Clinical Psychology, 58(9), 965-991. doi: 10.1002/jclp.10093 Heritage, J. (2001). Goffman, Garfinkel and conversation analysis. In M. Wetherell, S. Taylor, \& S. J. Yates (Eds.), Discourse theory and practice (pp. 47-56). London: Sage. Heritage, J. (2005). Conversation analysis and institutional talk. In K. L. Fitch, \& R. E. Sanders (Eds.), Handbook of language and social interaction (pp. 103-146). Mahwah, New Jersey: Lawrence Erlbaum.

Heritage, J. (2009). Conversation analysis as social theory. In B. S. Turner (Ed.), The new Blackwell companion to social theory (pp. 300-320). Oxford: Blackwell. 
Heritage, J. (2011). Territories of knowledge, territories of experience: Empathic moments in interaction. In T. Stivers, L. Mondada, \& J. Steensig (Eds.), The morality of knowledge in conversation (Studies in Interactional sociolinguistics No. 29, pp. 159183). Cambridge, UK: Cambridge University Press.

Heritage, J., \& Raymond, G. (2005). The terms of agreement: Indexing epistemic authority and subordination in talk-in-interaction. Social Psychology Quarterly, 68(1), 15-38. doi: 10.1177/019027250506800103

Hutchby, I. (2002). Resisting the incitement to talk in child counseling: Aspects of the utterance 'I don't know'. Discourse Studies, 4(2), 147-168. doi: $10.1177 / 14614456020040020201$

Jarrett, N. J., \& Payne, S. A. (2000). Creating and maintaining 'optimism' in cancer care communication. International Journal of Nursing Studies, 37, 81-90. doi: 10.1016/S0020-7489(99)00039-5

Jones, S. (2004). Putting the person into person-centered and immediate emotional support, emotional change and perceived helper competence as outcomes of comforting in helping situations. Communication Research, 31, 338-360. doi:

\section{$10.1177 / 0093650204263436$}

Jones, S. M., \& Bodie, G. D. (2014). Supportive communication. In C. R. Berger (Ed.), Interpersonal communication. Handbooks of Communication Science (Vol 6, pp. 371394). Berlin: De Gruyter Mouton.

Jones, S. M., \& Guerrero, L. K. (2001). The effects of nonverbal immediacy and verbal person centeredness in the emotional support process. Human Communication Research, 27, 567-596. doi: 10.1111/j.1468-2958.2001.tb00793.x

Jungert, T., \& Andersson, U. (2013). Self-efficacy beliefs in mathematics, native 
language literacy and foreign language amongst boys and girls with and without mathematic difficulties. Scandinavian Journal of Educational Research, 57(1), 1-15. doi: $10.1080 / 00313831.2011 .621140$

Lindström, A., \& Mondada, L. (2009). Assessments in social interaction: introduction to the special issue. Research on Language and Social Interaction, 42(4), 299-308. doi: $10.1080 / 08351810903296457$

Lindwall, O., \& Lymer, G. (2011). Uses of "understand" in science education. Journal of Pragmatics, 43, 452-474. doi: 10.1016/j.pragma.2010.08.021

Lounsbury, J. W. (2009). An investigation of the construct validity of the personality trait of self-directed learning. Learning and Individual Differences, 19(4), 411-418. doi: 10.1016/j.lindif.2009.03.001

Luthans, B. C., Luthans, K. W., \& Jensen, S. M. (2012). The impact of business school students' psychological capital on academic performance. Journal of Education for Business, 87, 253-259. doi: 10.1080/08832323.2011.609844

Lynch, M., \& Bogen, D. (2005). 'My memory has been shredded': a non-cognitivist investigation of 'mental' phenomena. In H. Molder \& J. Potter (Eds.), Conversation and cognition (pp. 226-240). Cambridge, UK: Cambridge University Press.

Mancini, F., D’Olimpio, F., \& Cieri, L. (2004). Manipulation of responsibility in nonclinical subjects: does expectation of failure exacerbate obsessive-compulsive behaviors? Behaviour Research and Therapy, 42, 449-457. doi: 10.1016/S0005-7967(03)00153-0 Martinez, N. I. (2009). Wishing clients well? An analysis of optimism work in 
conversations with seriously mentally ill clients (Doctoral dissertation). University of Chicago. Retrieved from Dissertation Abstracts International (Accession No. 201006843).

Mashburn, A. J., Pianta, R. C., Hamre, B. K., Downer, J. T., Barbarin, O. A., Bryant, D., Burchinal, M., Early, D. M., \& Howes, C. (2008). Measures of classroom quality in prekindergarten and children's development of academic, language, and social skills. Child Development, 79, 732-749. doi: 10.1111/j.1467-8624.2008.01154.x

Matsuoka, R., Smith, I., \& Uchimura, M. (2011). Discourse analysis of encouragement in healthcare manga. Journal of Pan-Pacific Association of Applied Linguistics, 15(1), 4966.

Metzger, T. R., \& Beach, W. A. (1996). Preserving alternative versions. Interactional techniques for organizing courtroom cross-examinations. Communication Research, 23(6), 749-765. doi: 10.1177/009365096023006006

Mondada, L. (2011). Understanding as an embodied, situated and sequential achievement in interaction. Journal of Pragmatics, 43(2), 542-552. doi:

10.1016/j.pragma.2010.08.019

Määttä, S., Stattin, H., \& Nurmi, J-E. (2002). Achievement strategies at school: types and correlates. Journal of Adolescence, 25, 31-46. doi: 10.1006/jado.2001.0447

Määttä, S., Nurmi, J-E., \& Stattin, H. (2007). Achievement orientations, school adjustment, and well-being: a longitudinal study. Journal of Research on Adolescence, 17(4), 789-812. doi: 10.1111/j.1532-7795.2007.00547.x

Nonis, S. A., \& Wright, D. (2003). Moderating effects of achievement striving and 
situational optimism on the relationship between ability and performance outcomes of college students. Research in Higher Education, 44(3), 327-346.

Nurmi, J-E., Aunola, K., Salmela-Aro, K., \& Lindroos, M. (2003). The role of success expectation and task-avoidance in academic performance and satisfaction: three studies on antecedents, consequences and correlates. Contemporary Educational Psychology, 28, 59-90. doi: 10.1016/S0361-476X(02)00014-0

Onatsu-Arvilommi, T., Nurmi, J-E., \& Aunola, K. (2002). The development of achievement strategies and academic skills during the first year of primary school. Learning and Instruction, 12, 509-527. doi: 10.1016/S0959-4752(01)00029-9

Patterson, D. (2011). Can I graduate from college?: The influence of ethnic identity, ethnicity, academic self-efficacy and optimism on college adjustment among community college students (Doctoral dissertation). Alliant International University, Los Angeles. Retrieved from ERIC database. (Record No. 533537)

Pekrun, R., Frenzel, A. C., Goetz, T., \& Perry, R. P. (2007). The control-value theory of achievement emotions: an integrative approach to emotions in education. In P. A. Schutz \& R. Pekrun (Eds.), Emotion in education (pp. 13-36). Amsterdam: Elsevier. Peräkylä, A. (1991). Hope work in the care of seriously ill patients. Qualitative Health Research, 1(4), 407-433. doi: 10.1177/104973239100100402

Peräkylä, A. (2004). Reliability and validity in research based on naturally occurring social interaction. In D. Silverman (Ed.), Qualitative research. Theory, method and practice (pp. 365-382). London: Sage. 
Peräkylä, A. (2011). A psychoanalyst's reflection on CA's contribution. In C. Antaki (Ed.), Applied conversation analysis: Iintervention and change in institutional talk (pp. 222-242). Hampshire, UK: Palgrave Macmillan.

Pomerantz, A. (1984). Agreeing and disagreeing with assessments: Some features of preferred/dispreferred turn shapes. In J. M. Atkinson \& J. Heritage (Eds.), Structures of social action. Studies in conversation analysis (pp. 57-101). Cambridge, UK: Cambridge University Press.

Phan, H. P. (2015). Maximizing academic success: Introducing the concept of optimized functioning. Education, 135(4), 439-456.

Phan, H. P. (2016). Longitudinal examination of optimism, personal self-efficacy and student well-being: a path analysis. Social Psychology of Education, 19, 403-426. doi: $10.1007 / \mathrm{s} 11218-015-9328-4$

Rudasill, K. M., Gallagher, K., \& White, J. M. (2010). Temperamental attention and activity, classroom emotional support, and academic achievement in third grade. Journal of School Psychology, 48, 113-134. doi: 10.1016/j.jsp.2009.11.002 Ruthig, J. C., Haynes, T. L., Perry, R. P., \& Chipperfield, J. G. (2007). Academic optimistic bias: Implications for college student performance and well-being. Social Psychology of Education, 10, 115-137. doi: 10.1007/s11218-006-9002-y

Ruusuvuori, J. (2013). Emotion, affect and conversation. In J. Sidnell \& T. Stivers (Eds.), The handbook of conversation analysis (pp. 330-349). West Sussex, UK: WileyBlackwell.

Scheier, M. F., \& Carver, C. S. (1985). Optimism, coping, and health: assessment and implications of generalized outcome expectancies. Health Psychology, 4(3), 219-247. 
Schulman, P. (1999). Applying learned optimism to increase sale productivity. The Journal of Personal Selling and Sales Management, 19(1), 31-37. doi:

$10.1080 / 08853134.1999 .10754157$

Seligman, M. E. P., \& Csikszentmihalyi, M. (2000). Positive psychology. An introduction. American Psychologist, 55(1), 5-14.

Schwab, S., \& Hessels, M. G. P. (2015). Achievement goals, school achievement, selfestimations of school achievement, and calibration in students with and without special education needs in inclusive education. Scandinavian Journal of Educational Research, 59(4), 461-477. doi: 10.1080/00313831.2014.932304

Snyder, C. R. (2002). Hope theory: Rainbows in the mind. Psychological Inquiry, 13(4), 249-275. doi: 10.1207/S15327965PLI1304_01

Su, Y. L., \& Reeve, J. (2011). A meta-analysis of the effectiveness of intervention programs designed to support autonomy. Educational Psychology Review, 23(1), 159188. doi: $10.1007 / \mathrm{s} 10648-010-9142-7$

ten Have, P. (2007). Doing conversation analysis. A practical guide ( $2^{\text {nd }}$ ed.). London: Sage.

Tetzner, J., \& Becker, M. (2017). Think positive? Examining the impact of optimism on academic achievement in early adolescents. Journal of Personality, 85(3), 1-13. doi: 10.1111/jopy.12312

Tschannen-Moran, M., Bankole, R. A., Mitchell, R. M., \& Moore, D. M. (2013). Student academic optimism: a confirmatory factor analysis. Journal of Educational Administration, 51(2), 150-175. doi: 10.1108/09578231311304689

Urdan, T. (2004). Predictors of academic self-handicapping and achievement: examining 
achievement goals, classroom goal structures, and culture. Journal of Educational Psychology, 96(2), 251-264.

Urdan, T., \& Schoenfelder, E. (2006). Classroom effects on student motivation: goal structures, social relationships, and competence beliefs. Journal of School Psychology, 44, 331-349. doi: 10.1016/j.jsp.2006.04.003

Viljaranta, J., Tolvanen, A., Aunola, K., \& Nurmi, J-E. (2014). The developmental dynamics between interest, self-concept of ability, and academic performance. Scandinavian Journal of Educational Research, 58(6), 734-756. doi: $10.1080 / 00313831.2014 .904419$

Wesson, C. J., \& Derrer-Rendall, N. M. (2011). Self-beliefs and student goal achievement. Psychology Teaching Review, 17(1), 3-12.

Yuen, M., Westwood, P., \& Wong, G. (2008). Self-efficacy perceptions of Chinese primary-age students with specific learning difficulties: A perspective from Hong Kong. International Journal of Special Education, 23, 110-119. 


\section{Appendix A. Transcription symbols}

Intonation:

Descending intonation

$\uparrow$

Ascending intonation

Pauses:

(.)

Brief, untimed pause, less than 1 second

The length of pauses of 1 second or more

Overlap:

Start of simultaneous talk

] End of simultaneous talk

$=\quad$ No discernible pause between the end of a speaker's utterance and the start of the next utterance

text- $\quad$ Interruption (unfinished word)

Rhythm:

$>$ text $<\quad$ Accelerated, talk between $><$ is spoken more quickly than surrounding talk

$<$ text $>\quad$ Slowed, talk between $<>$ is spoken more slowly than surrounding talk

: $\quad$ An extension of the preceding vowel sound

Strength of voice:

TEXT Spoken more loudly than the surrounding talk

text Spoken with emphasis

*text* Whispering

Other symbols:

ha-ha Laughing

Stext\$ Smiling

@text@ Changing one's typical voice

Comments from the transcriber:

(- -) Incomprehensible

$(($ text $)) \quad$ Comments from the transcriber 